\title{
SOME PROBLEMS IN THE FORMULATION OF A DISABILITY INSURANCE PROGRAM
}

\author{
I. S. FALK, $^{*}$ L. S. REED, † AND B. S. SANDERS**
}

In modern society, as in earlier times, the family remains the basic economic unit, but the ways in which a family obtains its livelihood have been greatly altered. In a nonindustrial society almost every member, excluding infants and very young children, can contribute to the family economy. In an industrial society the process of earning a living engages the activities of only one member or of a very few members of the family. The economic security of nine in every ten American families now depends chiefly on the earnings of one individual. Any serious interruption in his earnings, whether through unemployment, disabling disease, accidental injury, or old age causes economic insecurity; and may precipitate destitution and even disruption of the family.

Conscious of this fundamental change in the methods of earning a living, and appalled by the devastating effects of the depression, the United States has followed the example of other nations in developing social insurance. Measures have already been adopted to mitigate the insecurity attendant upon loss of earnings through old age or unemployment. The workmen's compensation laws, enacted by the federal government for certain groups subject to its jurisdiction and by 47 of the states for workers in various industries and occupations, provide insurance against disability

- Ph.B., 1920; Ph.D., 1923, Yale University. Assistant Director, Bureau of Research and Statistics, Social Security Board. Member of the (Interdepartmental) Technical Committee on Medical Care. Fellow, American Public Health Association, American Association for the Advancement of Science, American Academy of Political and Social Science, etc. Author of Principles of Vital Statistics (I923); ORganized Medical Service at Fort Benning, Ga. (1932); The Incidence of Iliness and the Receipt and Costs of Medical Care Among Representative Families (with M. C. Klem and N. Sinai) (I933); The Costs of Medical Care (with C. R. Rorem and M. D. Ring) (1933); Security Against Sickness: A Study of Health Insurance (1936). Contributor to professional and lay periodicals.

† A.B., Amherst College, I924; Ph.D., Columbia University, 1930. Chief, Medical Economics Section, Health Studies Division, Bureau of Research and Statistics, Social Security Board. Author of THE LABOR Phlosophy of Samuel Gompers (1930); The Healing Cults (1932); The Ability to Pay for Medical Care (1933); Health Insurance: The Next Step in Social Security (1937).

* B.A., 1926, State Teachers College, Massachusetts; M.A., 1927, Ph.D., I933; Columbia University. Member, District of Columbia Bar. Chief, Statistical Section, Division of Health Studies, Bureau of Research and Statistics, Social Security Board. Statistician for the Committee to Study Compensation for Automobile Accidents, Columbia University Council for Research in Social Sciences, I931-I932; Technical Director, Attorncy General's Survey of Relief Procedures, 1935-1937. Author of ENvironment AND Growtr (1934), and other publications, mostly in the field of criminology.

The opinions expressed in this article are the authors' and are not to be taken as representing the views of the Social Security Board. 
resulting from employment. Hence, a considerable proportion of the working population of the country now has some protection against the risks of old age, unemployment, and industrial disabilities. No extensiye provisions have, however, been made to protect workers against interruption of earnings brought about by disabling diseases and non-industrial accidents. This is a serious gap in the bulwark's against insecurity because in our industrial economy disability is one of the major causes of interruption of earnings.

The National Health Program, developed by the Technical Committee on Medical Care (a subcommittee of the President's Interdepartmental Committee to Coordinate Health and Welfare Activities) included proposals for social insurance against disability. Among the four broad recommendations submitted by the Interdepartmental Committee in its report of January 12, 1939, to the President, ${ }^{1}$ was the following:

D. The committee recommends the development of social insurance to insure partial replacement of wages during temporary or permanent disability.

The committee indicated its belief that insurance against temporary disability should be established through federal-state cooperative arrangements, and that insurance against permanent disability should be effected through liberalization of the federal old-age insurance system, so that benefits would become payable at any time prior to age 65 to qualified workers who become permanently and totally disabled.

In bringing into legislative form the recommendations of the Interdepartmental and Technical Committees, Senator Wagner divided the disability proposals. The basis for a federal-state system of temporary disability insurance was provided through Title XIV of his proposed "National Health Act of 1939," S. I620. The expansion of the federal system of old-age insurance to furnish permanent and total disability (invalidity) benefits was proposed ${ }^{2}$ through an amendment to H. R. 6635, which. eventually became the "Social Security Act Amendments of 1939."

Neither S. I620 nor the disability amendments to H. R. 6635 were enacted. However, in the Preliminary Report on S. 1620 to the Senate from the Committee on Education and Labor, Senator Murray, chairman of the subcommittee which had conducted the hearings on this bill, said:

The committee ... cannot ignore the problems created by permanent disability when it studies measures to deal with temporary disability, despite the fact that proposals for permanent disability benefits were not specifically included in the bill under consideration. A system for permanent disability compensation must be reasonably related to old-age -insurance, and such a system has been under consideration by another committee of the Senate studying amendments to title II (old-age insurance) of the Social Security Act. Developments in this field and the need for permanent-disability compensation legislation will be considered carefully by our committee in connection with title XIV of S. $16200^{3}$

Taken together, Title XIV of S. I620 and the proposed amendments to H. R. $66_{35}$ constitute a logical pattern for the development of social insurance against loss of

1 H. R. Doc. No. 120, 76th Cong., Ist Sess. p. I6.

${ }^{2}$ Social Security Act Amendments: Hearings before the Sen. Committee on Finance, on H. R. 6635 (revised, 1939) 76th Cong., ist Sess., pp. 296-305. $\quad{ }^{3}$ S. Rep. No. 1139, 76th Cong., Ist Scss., 1. 23. 
earnings by reason of disability. Other patterns are, however, possible and defensible and deserve careful consideration.

This paper is primarily concerned with underlying characteristics of disability problems and with some of the considerations which should be weighed and examined in the formulation of a disability insurance program. A brief review of fundamental facts concerning the incidence and the prevalence of disability, and. the economic consequences of disablement, will furnish a background for these considerations.

\section{The Need for Disability Insurance}

The need for disability insurance may be shown by (a) the amount of dependency traceable to disabling illness, and (b) the wage losses due to disabling illness, their distribution, and the magnitude of such losses in relation to earnings.

Dependency Caused by Disability. The proportion of dependency attributable to disabling illness varies from time to time, the relative importance of disability as a cause of dependency being greater in years of prosperity, when there is little unemployment, than in years of severe depression, when there is much unemployment. In IgIg the Ohio Health and Old Age Insurance Commission reported:4

For the United States the consensus of opinions from all responsible sources is that from 35 per cent to 50 per cent of the poverty which asks for relief is directly due to sickness. As the result of an investigation covering forty-three cities and over 30,000 charity cases, the United States Immigration Commission reported in 1909 that illness of the breadwinner or other member of the family was a factor in 38.3 per cent of the cases seeking aid. In New York City, "sickness or deformity" were present in two-thirds of the 3,000 families assisted by the Charity Organization Society in the first five months of 1916; in Chicago sickness is reported as the primary factor in 25 per cent of the cases cared for in 1917 by the United Charities, and as a contributory factor in 45 per cent of the other cases; in San Francisco and Los Angeles sickness was the primary cause of destitution in 50 per cent of over 5,000 charitable cases.

For Ohio, the investigations made for the Commission show that sickness is the leading cause of dependency. In Cleveland, the Associated Charities reports that in I9I7, 5I per cent of their cases were due to sickness; Columbus reports 25 per cent of the applications are due directly to sickness and that sickness is present in 74 per cent of cases; Newark, $3^{6}$ per cent; Springfield, 30 per cent and Toledo, 35 per cent. In Cleveland, an examination covering a three year period of the. Associated Charities' records was made for the purpose of determining the proportion of disability, other than that due to industrial accident, present among those applying the first time for relief. The results showed that out of 6,272 cases seeking relief for the first time, disability was present in 2,II2 or 33.7 per cent.

The Illinois Health Insurance Commission, in a report submitted in I9I9, said: 5

Investigations made elsewhere than in Illinois show that disabling sickness may be charged with about a quarter of dependency not cared for in almshouses and similar institutions. The reports made to the Commission by charity organization societies of eight Illinois cities assign sickness as the chief cause of approximately one-third of all dependency

\footnotetext{
- Ohio Health and Old Age Insurance Comm'n, Health, Health Insurance, Old Age Penstons (1919) $59-60$.

'Ilz. Health Insurance Comm'n Report (May i, igrg) 20.
} 
in I9I7-I9I8. Our investigation of the data provided by Chicago charitable agencies for an eight year period indicates that physical and mental disability is designated in one-third to one-half of all analyzed causes and problems of dependency. The lower dependency ratio ascribed to sickness by other investigators was found to be due to the fact that their studies were made in years abnormal for poverty and dependency by reason of an unusual degree of unemployment.

As these and other reports indicated, in years of normal employment as much as $50 \%$ of all dependency could be attributed largely, if not entirely, to disabling disease. In a period of extensive unemployment such as this country has experienced in the last decade, the relative volume of dependency attributable to disabling sickness would be smaller.

Recent statistical (as distinguished from case) studies have not always lent themselves to an unequivocal determination of the relative importance of sickness as a cause and as a consequence of illness. Some of these have, nevertheless, cast considerable light on disability as a cause of dependency.

In 1933, the United States Public Health Service examined the association between disabling disease and change of family income status. ${ }^{6}$ The study was based on the illness records for a three-month period in 1933 among 12,000 wage-earning families in eight cities, a group of coal-mining communities, and a group of cotton-mill villages. It was found that the rate of disabling illness was $48 \%$ higher among families having no employed wage earners in 1932 than among families having full-time workers. The group of families which had dropped from fairly comfortable circumstances to relief rolls during the depression years showed a rate of disabling illness $73 \%$ higher than that of their more fortunate neighbors who had remained in the comfortable class throughout the four-year period. This study gave unmistakable evidence that the sharpest change in income status occurred among families experiencing disabling illness in 1933 .

A study made in $1934,{ }^{7}$ based on a house-to-house canvass of more than 165,000 relief families in 79 cities, indicated that $21 \%$ of the individuals in these families, in ages 16 and over, reported serious handicaps. Among persons of wage-earning ages, that is 16 to $64,15 \%$ of those seeking work and $27 \%$ of those not seeking work were reported as being seriously handicapped. The latter proportion would have been much higher had it been possible to exclude from this class women who were not seeking work because of home duties. In the course of this study, in Dayton, Ohio, where the survey included nonrelief as well as relief families, it was found that the prevalence of disabilities among persons on relief was three times as great as among those not on relief.

An analysis of the relief population of seven Maryland counties in $1934^{8}$ indicated that among persons of wage-earning ages who were working or seeking work $22 \%$

- Perrott and Collins, Relation of Sickness to Income and Income Change in ro Sturveyed Communities (1935) 50 PUBzic Health Reports, No. 18, pp. 595-622.

"Perrott and Griffin, An Inventory of the Serious Disabilities of the Urban Relief Population (1936) 14 Milbank Memorial Fund Q. 213-240.

'Manny and Clowes, An Analysis of the Relief Population in Selected Areas of Maryland, (Mim. Circ. No. I, Univ. of Md. Social Research Studies, Aug. 1937). 
had serious disabilities. A Michigan study ${ }^{9}$ showed that of $x 92,000$ cases on the state's emergency relief rolls at the end of January 1935, over 37,000, or more than $19 \%$, contained no employable individuals.

The National Health Survey demonstrated that among more than 650,000 families in $8 \mathrm{r}$ cities the following proportions reported that the head of the family was not gainfully employed or seeking work because of chronic disability: ${ }^{10}$

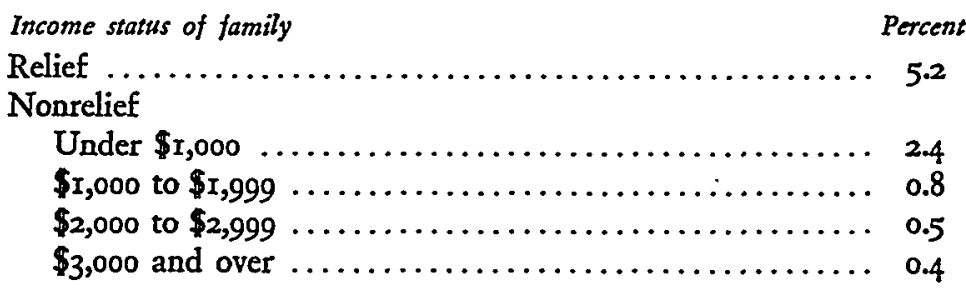

The same study showed that the frequency of illness, especially of chronic illness, was markedly greater in families reporting relief than in families having incomes of $\$ 3,000$ and over. The incidence of acute disease among relief families was $47 \%$ higher than among families with incomes of $\$ 3,000$ and over, and the incidence of chronic disease $87 \%$ higher for the relief families. ${ }^{11}$ These discrepancies become even larger if the duration of disability is considered. Regarding days of disablement of individuals in families with incomes of $\$ 5,000$ and over as roo, the corresponding values for persons aged $1_{5}$ to 24 in families on relief would be 267 , and for ages 25 to 64,35 r. $^{12}$

In a study of nearly $50,000 \mathrm{New}$ Jersey cases on relief on November $30,1937,{ }^{13}$ it was found that more than $25 \%$ were families without employable individuals, and in almost half of these families the lack of an employable individual was attributed to disabling disease. In the families with one or more employable members, $7 \%$ of the adults were seriously disabled. In New York City, of 158,000 cases accepted for relief during $1938,15,000$ or approximately $10 \%$ were persons who had lost their jobs in private industry because of illness. ${ }^{14}$

In interpreting the significance of these statistics, and of many similar reports which could be cited, it-should be kept in mind that, in many cases, although a dépendent family may have no disabled worker at the time of a canvass, disability may have been the initial link in the chain of events which rendered the family dependent. Although available studies are inconclusive as to the precise proportion of dependency

\footnotetext{
${ }^{\circ}$ Mich. State Emergency Welfare Relief Comm'n, Unemployable Persons on the Emergency Relief Rolls in Michigan (March r935).

${ }^{10}$ Nattonal Health SURvex: 1935-36, Illness and Medical Care in Relation to Economic Status, Sickness and Medical Care Series, Bull. 2, U. S. Pub. Health Service (I938) 3.

${ }^{11}$ Id. at 2.

${ }^{19}$ Computed from id., Disability from Specific Causes in Relation to Economic Status, Sickness and Medical Care Series, Bull. 9, U. S. Pub. Health Service (1938) 2.

${ }^{13}$ N. J. Financial Assistance Comm'n, Persons Reported With Chronic Physical Disabilities in the New Jersey Relief Census of November 30, 1937 (June 1939).

14 Hodson, Correlating Unemployment Insurance and Home Relief, SOctaI SECURITY IN THE UNITED States, 1939: A Record of the 'Twelfth Nattonal Conference on Social Securaty (Am. Ass'n for Social Security, Inc., 1939) i32-I42.
} 
that may be attributed to disabling disease and nonindustrial accident, they indicate quite definitely that even in periods of severe unemployment disabling illness is the cause of a considerable proportion of dependency. When unemployment is less prevalent, disability rises to high rank among the principal causes of dependency.

Extent of Disability. A precise statement of the volume and incidence of disability among gainful workers cannot be made from available data, and probably must await the actual operation of a system of disability insurance. Until such time, estimates must be based upon the data that have become available from various sickness surveys and from the experience of private insurance companies, employee or fraternal mutual benefit insurance, public retirement, and disability plans, etc., each of which is limited in scope and in coverage. In comparison with these the disability statistics derived from foreign social insurance experience, with appropriate adjustment and standardization, may offer more dependable guidance.

The most recent and comprehensive sickness study in this country is the National Health Survey conducted by the United States Public Health Service in the winter of $x 935-36$. This survey consisted of a house-to-house canvass of some 800,000 households, involving 2,800,000 persons in 84 cities distributed among I9 states and in 23 rural counties in 3 states. When the findings of this survey are applied to the population of the United States, it appears that on any day during the winter months about $4.5 \%$ of the population, or almost 6 million individuals, are unable to work, attend school, or pursue other usual activities on account of illness, injury, or gross physical impairment resulting from illness, accident, or congenital defects. ${ }^{15}$ Although more illness and disability prevails during the winter months of the year, there is, nevertheless, good reason to believe that, large as the above figures are, they materially understate the prevalence of disability on an average day..$^{16}$

Preliminary returns from the same survey indicate that among gainfully employed white persons aged 15 to $64,2.36 \%$ were disabled on the day of the canvass. The prevalence of disability was found to be considerably greater among unemployed than among employed individuals, and greater among females than among males. Thus, it was found that $3.95 \%$ of the unemployed were disabled on the day of the canvass, as compared with $\mathrm{r} .95 \%$ of those who held jobs; and that $2.20 \%$ of male gainful workers were disabled, as compared with $2.77 \%$ of female workers. ${ }^{17}$ The prevalence figures of the National Health Survey indicate that gainful workers in ages 15 to 64 average 8.6 days of disability per year; for males the figure is 8.0 , and for females ro.x..$^{18}$

If these figures were used to anticipate the volume of disability to be expected under an insurance system, they would be too low for at least two reasons, even

\footnotetext{
${ }^{28}$ National Health Survey: 1935-36, An Estimate of the Amount of Disabling Illness in the Cointry as $a$ Whole, Sickness and Medical Care Series, Bull. I, U. S. Pub. Health Service (1938) 1.

${ }^{10}$ This understatement results from the underreporting and exclusion of certain categories of disabled persons, such as persons in mental hospitals, and from underenumeration inherent in a canvass of this type.

${ }^{17}$ Natjonal Health SuRvey: 1935-36, Illness Among Employed and Unemployed Workers, Sickness and Medical Care Series, Bull. 7, U. S. Pub. Health Service (1938) 3.

${ }^{18}$ Computed from National Health Survey: 1935-36, supra note 17.
} 
assuming that the reporting were complete: (I) In the absence of insurance compensation many workers who are ill and who ought not be at work continue working because of economic pressure; and (2) disabled persons who have been out of the labor market for some time because of their disability will not ordinarily be included in the statistics of gainful workers.

That the extent of disabling illness, among those who are or who have been gainfully employed workers, is appreciably greater than the crude averages derived from the National Health Survey is indicated by various insurance experiences, domestic and foreign. Thus, in I927 the study of a sample population covered under the British National Health Insurance indicated that insured workers averaged 14.6 compensable days of incapacity during a year. ${ }^{19}$ When this figure is adjusted to allow for the volume of incapacity incurred within the three-day waiting period, the average amount of disability experienced under the National Health Insurance is approximately 55.6 days. It should be remembered, however, that the National Health Insurance is limited to manual workers and to nonmanual workers with incomes of less than $\$ 250$ a year. Since the volume of disability is relatively large among low income groups, it is probable that the volume of sickness experienced among the gainfully employed in the United States is somewhat less than that shown by this British experience.

In Scotland, the average annual per capita number of compensable days of incapacity has been as follows among persons covered by the National Health Insurance:

\begin{tabular}{|c|c|c|}
\hline $\begin{array}{c}\text { Year } \\
\text { (July I- } \\
\text { June 30) }\end{array}$ & $\begin{array}{l}\text { Days of } \\
\text { incapacity } \\
\text { (including } \\
\text { influenza) }\end{array}$ & $\begin{array}{l}\text { Days of } \\
\text { incapacity } \\
\text { (excluding } \\
\text { influenza) }\end{array}$ \\
\hline 1930-I. & IO.I & 9.2 \\
\hline I93 I-2. & 9.9 & 8.8 \\
\hline I932-3.. & 10.9 & 9.5 \\
\hline I933-4.. & I0.0 & 9.9 \\
\hline r934-5. & I0.9 & I0.6 \\
\hline I935-6.. & II.4 & II. 2 \\
\hline x936-7.. & 14.9 & 10.9 \\
\hline
\end{tabular}

Again, these averages would have to be increased by about one day per capita per annum, to take account of the three-day waiting period.

The German workers' insurance experience ${ }^{20}$ shows a much higher volume of compensable disability, namely, an average of 28.3 days per insured worker in r933, and when allowance for the three-day waiting period is made this figure becomes

\footnotetext{
${ }^{20}$ Calculated from data given by Watson, The Analysis of a Sickness Experience (193I) 62 J. of THE INST. OF ACtUARIEs, pt. $\mathrm{r}$, pp. ז2-6r.

${ }^{20}$ Adjusted for the age and sex proportions of the U. S. old-age insurance population with wage credits recorded for 1937. When the British experience cited above is similarly adjusted, the average amount of disability is increased from 15.6 days per capita per annum by approximately 0.5 .
} 
about 29.3. This greater volume is partly to be explained in terms of the much more liberal benefit formulas of the German sickness and invalidity insurance systems, the effects of the World War, and the fact that this average applies exclusively to manual workers. (Salaried workers are covered in a separate insurance system.) Again, these figures include temporary and permanent compensable disability among those who have dropped out of the labor market as well as those who are still among the gainfully employed.

On the basis of foreign experience and data available in the United States, it may be estimated that the average annual volume of disability for gainful workers in the United States may be as much as about $\mathrm{I}_{2}$ days per person. On this basis, the total loss in wages incurred would be more than one billion dollars in a year of moderate unemployment. This loss is all the more serious because it falls on a relatively small number of families in any year. This is illustrated by the figures given in the following tabulation, showing the distribution of disabilities lasting 8 days or more among 60,000 white male railroad employees.

Number and Percent Distribution of Disability Cases and of Volume of Disability, by Duration. Experience Based on Disabizity Lasting Eight Days or More Among 60,000 White Male Railroad EMployees, 1930-I934 INCLUSIVE. ${ }^{1}$

\begin{tabular}{|c|c|c|c|c|c|c|c|c|}
\hline \multirow{2}{*}{ Duration } & \multicolumn{2}{|c|}{$\begin{array}{l}\text { NUMBER OF CASES } \\
\text { PER } 1,000 \text { EXPOSEd }\end{array}$} & \multicolumn{2}{|c|}{$\begin{array}{c}\text { Percent of } \\
\text { Disabled Cases }\end{array}$} & \multicolumn{2}{|c|}{$\begin{array}{c}\text { NuMber of DAYS } \\
\text { or DisABILITY PER } \\
1,000 \text { EXPOSED }\end{array}$} & \multicolumn{2}{|c|}{$\begin{array}{l}\text { Percent of Total } \\
\text { Days of Disability }\end{array}$} \\
\hline & $\begin{array}{l}\text { Specified } \\
\text { duration }\end{array}$ & $\begin{array}{l}\text { Specified } \\
\text { and longer } \\
\text { duration }\end{array}$ & $\begin{array}{l}\text { Specified } \\
\text { duration }\end{array}$ & $\begin{array}{l}\text { Specified } \\
\text { and longer } \\
\text { duration }\end{array}$ & $\begin{array}{l}\text { Specified } \\
\text { duration }\end{array}$ & $\begin{array}{l}\text { Specified } \\
\text { and longer } \\
\text { duration }\end{array}$ & $\begin{array}{l}\text { Specified } \\
\text { duration }\end{array}$ & $\begin{array}{l}\text { Specified } \\
\text { and longer } \\
\text { duration }\end{array}$ \\
\hline $\begin{array}{r}8-14 \text { days..... } \\
15-28 \text { days..... } \\
29-49 \text { days..... } \\
50-70 \text { days..... } \\
71-91 \text { days..... }\end{array}$ & $\begin{array}{r}40.81 \\
36.67 \\
20.18 \\
9.23 \\
5.26\end{array}$ & $\begin{array}{r}131.46 \\
90.65 \\
53.98 \\
33.80 \\
24.57\end{array}$ & $\begin{array}{r}31.0 \\
27.9 \\
15.4 \\
7.0 \\
4.0\end{array}$ & $\begin{array}{r}100.0 \\
69.0 \\
41.1 \\
25.7 \\
18.7\end{array}$ & $\begin{array}{l}464.37 \\
761.81 \\
768.90 \\
548,04 \\
426.20\end{array}$ & $\begin{array}{l}9,750.84 \\
9,286.47 \\
8,524.66 \\
7,755.76 \\
7,207.72\end{array}$ & $\begin{array}{l}4.8 \\
7.8 \\
7.9 \\
5.6 \\
4.4\end{array}$ & $\begin{array}{r}100.0 \\
95.2 \\
87.4 \\
79.5 \\
73.9\end{array}$ \\
\hline $\begin{array}{l}13-26 \text { weeks. . } \\
26-39 \text { weeks. . } \\
39-52 \text { weeks. . }\end{array}$ & $\begin{array}{l}8.95 \\
2.86 \\
1.88\end{array}$ & $\begin{array}{r}19.31 \\
10.36 \\
7.50\end{array}$ & $\begin{array}{l}6.8 \\
2.2 \\
1.4\end{array}$ & $\begin{array}{r}14.7 \\
7.9 \\
5.7\end{array}$ & $\begin{array}{r}1,110.68 \\
633.44 \\
602.64\end{array}$ & $\begin{array}{l}6,781.52 \\
5,670.84 \\
5,037.40\end{array}$ & $\begin{array}{r}11.4 \\
6.5 \\
6.2\end{array}$ & $\begin{array}{l}69.5 \\
58.1 \\
51.6\end{array}$ \\
\hline $\begin{array}{l}1-2 \text { years.... } \\
2-3 \text { years.... } \\
3-4 \text { years... } \\
4-5 \text { years... }\end{array}$ & $\begin{array}{l}3.08 \\
1.31 \\
0.77 \\
0.46\end{array}$ & $\begin{array}{l}5.62 \\
2.54 \\
1.23 \\
0.46\end{array}$ & $\begin{array}{l}2.3 \\
1.0 \\
0.6 \\
0.4\end{array}$ & $\begin{array}{l}4.3 \\
2.0 \\
1.0 \\
0.4\end{array}$ & $\begin{array}{r}1,527.28 \\
1,186.05 \\
977.09 \\
744.34\end{array}$ & $\begin{array}{r}4,434.76 \\
2,907.48 \\
1,721.43 \\
744.34\end{array}$ & $\begin{array}{r}15.6 \\
12.2 \\
10.0 \\
7.6\end{array}$ & $\begin{array}{r}45.4 \\
29.8 \\
17.6 \\
7.6\end{array}$ \\
\hline Total.......... & 131.46 & $\cdots$ & 100.0 & $\cdots$ & $9,750.84$ & & 100.0 & $\cdots$ \\
\hline
\end{tabular}

1 Based on data from Gafafer, Frequency of Sickness and Nonirdustrial Accidenes Causin Disability Lasting Eight Calendar Days or Longer Among 60,000 Whits Male Railroad Employees, 1930-34, Inclusize (1938) 53 PuBuc Hzasta RupouTa, No. 15, pp. 555-573.

Of the total number of disabling cases, exclusive of cases lasting one week or less, at one extreme almost one third involved disability lasting 8 to $\mathrm{I} 4$ days; and these cases accounted for only $4.8 \%$ of all disability. At the other extreme, $4.3 \%$ of the cases involved disabilities lasting a year or longer and accounted for $45.4 \%$ of all disability.

In an average year, while a large proportion of families may suffer little or no loss of earnings from disability, about i0-20\% may suffer losses that are substantial. 
In each year about $\mathrm{x} \%$ of the families may permanently lose the earnings of their chief breadwinner. Thus, a large part of the annual wage loss due to disability will be borne by a small part of the population. Because the rates of disability are higher the lower the income level, the burden falls most heavily on those least able to bear it. In the cases most seriously affected, the losses are frequently large enough to wipe out whatever savings the family may have and in many instances large enough to carry them below the level of self-support. This is illustrated by preliminary results obtained from a study of family composition in the United States which indicate that approximately $50 \%$ of families in which the head was not seeking employment because of disability were on relief. ${ }^{21}$

In Europe, because of earlier industrialization and the relatively lower incomes of the working population, the need for protective measures against disabling disease became evident sooner than in the United States. In the nineteenth century wage earners banded together through fraternal societies, lodges, unions, and other mutual assistance organizations to provide themselves with insurance protection against sickness and invalidity. Valuable as these voluntary systems were, they proved inadequate to cope with the problem, and gradually one nation after another adopted compulsory insurance to provide compensation for disability. Today, some $3^{2}$ nations have compulsory systems of sickness and invalidity insurance covering at least all or almost all the manual workers. ${ }^{22}$ Of the nations which now have insurance against sickness and invalidity, 2I have both, 6 have insurance against invalidity only, and 6 have insurance against sickness only.

In the United States, there is some voluntary insurance against disability. It is estimated that almost 8 million wage earners possess some form of insurance against temporary disability; however, for a large proportion of these warkers the protection afforded by such insurance is very slight. It is estimated that about 20 million wage

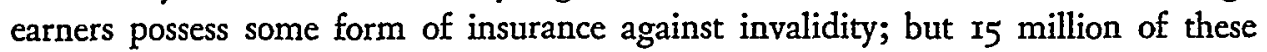
are workers holding industrial insurance, and most of their policies are so restricted in scope as to provide no substantial protection. ${ }^{23}$ The vast majority of employed persons in this country have no real or substantial protection against the risk of loss of earnings from disability. The experience of foreign countries indicates that there is little likelihood that the situation will be fundamentally altered in the future unless governmental action is taken to make broader and more substantial insurance protection available to gainfully occupied workers.

\section{The Problem of Distinguishing Temporary Disability and Invalidity}

In formulating a program of disability insurance the first question is to decide whether one program should be adopted for all disability cases or whether two pro-

${ }^{21}$ Sanders, Family Composition in the United States (1939) 2 Soctat SEcuRITY Bulr. No. 4, pp. 9-13.

12 A considerable number of other countries have temporary disability and invalidity insurance covering various segments of their working population. These, however, have been excluded from the count given above, which includes only countries where the coverage is extended at least to all or almost all the manual workers.

${ }^{28}$ Otey, Cash Benefits Under Voluntary Disability Insurance (1939) 2 SociaI Security Bulz. No. 2, pp. 27-33. 
grams should be evolved, one for short-time disabilities and the other for disabilities of long duration or of a permanent character.

In general, cases of disability may be classified in three types. At the one extreme, there is temporary or short-time disability resulting, in the main, from acute illness, and causing a temporary interruption of earnings. At the other extreme, there is permanent total disability resulting from chronic disease or from injuries causing loss of limb, sight, etc. In such cases the disabled person will be incapacitated for the remainder of his life and will require support until death. Between these extremes there is a third type consisting of cases of disability which are neither temporary, in the sense of lasting but a short time, nor permanent, in that disability will endure until death. These are cases of long-continued illness which persist for a long period before they terminate in recovery or are judged to be permanent in nature. Many cases of this type can be separated from either temporary or permanent disability only by arbitrary criteria. For example, in many cases of chronic disease physicians will be reluctant to render a definite judgment whether the patient will or will not be permanently disabled.

Many characteristics of long-continued illness are similar to those of permanent disability. Administrative and financial problems in providing insurance, protection are also similar. It is, therefore, logical to draw these two types together. This is generally the practice in foreign social insurance systems; long-continued or chronic illnesses and permanent disability, taken together, are known as invalidity.

A single system of disability insurance could be established to compensate both temporary disability and invalidity. Such a procedure would have some obvious and important advantages. It would permit easy coordination or integration of the disability insurance system with any system or systems for the provision of medical care; and it would avoid the necessity of making a more or less arbitrary distinction between types of disability which shade imperceptibly into each other. With a single system, gaps in a disability insurance program could be more easily avoided than if there were two separate systems. Medical examination of claimants is necessary in both temporary disability and invalidity, in order to ascertain whether disability exists, and the utilization of common facilities for this purpose would have obvious advantages.

There are also important considerations which argue for differentiation of temporary disability from invalidity and for setting up separate, though coordinated, insurance systems to deal with each type. There are substantial reasons why the benefit rate should be less for invalidity than in temporary disability cases. The criteria in judging and certifying the presence of disability in the two cases should differ in important respects. The concentration of invalidity cases in the older ages argues for a smooth coordination of invalidity and old-age benefits, though such a relationship with old age is much less important for temporary disability. The finances of the two types of insurance have important differences; temporary disability occurs relatively frequently but the benefits are relatively inexpensive in the individual case, 
and the reverse is true for invalidity; furthermore, maturity is reached quickly in temporary disability insurance, but only after the lapse of 15 or more years in permanent disability insurance. The relatively high cost of benefits in individual invalidity cases justifies stricter eligibility conditions in an insurance system of limited coverage than would be necessary for temporary disability. The need for repetitive certification of temporary disabilities, as against infrequent recertification of invalidity, implies some fundamental differences in the administration mechanism.

These and other differences in the problems of insuring against temporary disability and invalidity must be given careful consideration, but they must not be permitted to obscure the important points of similarity between the two.

There is only one foreign system of social insurance, the British, which treats all disability as a continuing risk, no matter how long the disability lasts. But even the British system makes certain distinctions between temporary as against longcontinued and permanent disability. The rate of benefits is reduced one half after disability has lasted six months, and the criterion of disability is changed as soon as it becomes apparent that an individual will be unable to engage in his former line of work. All other foreign social insurance systems have linked invalidity insurance with old-age insurance (many of these systems calculate the pensions payable in invalidity and old age by the same basic formula) and generally they have linked temporary disability with medical care insurance, the combined system being known as health or sickness insurance.

In foreign systems, the distinction between temporary disability and invalidity is made in various ways. In Great Britain the line is drawn on a time basis, that is, the worker is entitled to draw temporary disability ("sickness") benefits for a maximum of 26 weeks in a year; if disability still persists he goes on invalidity ("disablement") benefit at half the rate of the sickness benefit. In Germany the sickness insurance system is responsible for paying benefits during the first six months of disability in illnesses which are not considered likely to result in permanent disability. In cases which are judged to be permanent the invalidity insurance system pays the benefits from the outset or as soon as a prognosis of permanency is made; this system also pays the benefits in all cases of disability lasting beyond six months. In France the sickness insurance system pays benefits during the first six months of any illness; at the expiration of this period the invalidity insurance system becomes responsible. The same procedure was followed in Czechoslovakia, except that the line of demarcation was drawn at the expiration of a year's period.

If the distinction between temporary disability and invalidity is made according to the criterion of duration only, the line must be drawn at some arbitrary point. There is nothing in the frequency curve for illnesses of different durations which would indicate that the dividing line should be drawn at 26 weeks, 39 weeks, a year, or at any subsequent point. The distinction between temporary disability and invalidity may be drawn at whatever point is desirable in the light of economic and social considerations. 
Foreign experience suggests that, if it is found desirable to make a distinction in the United States between temporary disability and invalidity, the line of demarcation may be drawn in one of several ways. We could follow the pattern of the British health insurance system and, avoiding the problems involved in the certification of permanency of disability, draw the line at, say, I3 weeks, 26 weeks, 39 weeks or one year. Or we might follow the German example, namely, to draw the line at six months' duration but to classify all cases 'of permanent disability as invalidity sooner if a prognosis of permanent disability is made before the expiration of six months. Still a third approach might be to distinguish the cases which are clearly permanent disability and to classify all other cases as temporary disability; if the temporary disability benefits are more generous in such a plan than those given in the cases judged to be permanent, it would probably be desirable or necessary to reduce the amount or the rate of temporary disability benefits after such benefits have been paid for a specified number of weeks.

Drawing the line of demarcation solely on a time basis has the following advantages: (I) It eliminates the problem of deciding, in specific cases, whether or not disability is likely to be permanent; (2) it allows the disabled person to know definitely what benefit he may expect-the amount of his benefit will not hinge upon a physician's prophecy of permanent or temporary disability; (3) during the period for temporary disability benefits, it assures both the permanently disabled person and the person suffering from illness which may or may not result in permanent incapacity of receiving the same amount of benefits. This permits the permanently disabled person to make a gradual adjustment in his standard of living. In foreign countries which place permanent disability under the jurisdiction of invalidity insurance as soon as a prognosis of permanency is made, there is often a jurisdictional problem between the sickness insurance and the invalidity insurance institutions, each having an interest in avoiding the payment of benefits in cases which they consider should be the responsibility of the other.

The question of how to draw the line of demarcation between temporary disability and invalidity will be influenced very greatly in the United States by the administrative problems involved in coordinating or integrating the social insurance programs. This question is complicated by the fact that old-age insurance is now administered by the federal government, and unemployment and workmen's compensation by the states, while the administrative level for health insurance has not yet been decided.

From what has already been said it is evident that a number of different administrative linkages are possible. Thus, insurance against invalidity might be integrated with the federal old-age and survivors insurance, and temporary disability insurance might then be linked with (a) medical-care insurance, (b) unemployment compensation, or (c) workmen's compensation, all on a state level. Or insurance against invalidity and temporary disability could be instituted through a single system, which might be either federal or state. A federal system could be integrated into or co- 
ordinated with old-age and survivors insurance and with federal medical-care insurance; a state system could be linked with medical-care insurance, workmen's compensation, or with unemployment compensation, all on a state level. Other combinations are conceivable. In any case, some close relationship should exist between disability insurance and medical-care insurance. Both are concerned with the prevention of illness and disability. It is probably inevitable and desirable that the physician who treats the sick and disabled worker should render a contributory opinion as to whether the worker is disabled and when he is able to return to work. The issues involved in these questions of administrative coordination or integration of the various social insurance programs are complex and among the most important involved in designing a program of disability insurance.

\section{Formulation of Specifications}

In formulating a system of disability insurance, various problems must be faced in determining the specifications, irrespective of whether compensation in both types of disability is made through a single unified system or through two more or less separate systems. The precise answers which may be given are, of course, influenced according to whether a single or a dual system is to be established. In discussing together the problems for both temporary disability and invalidity we do not intend in this paper to prejudice the question whether a single unified system or a dual, system is to be preferred.

\section{Coverage}

To what population groups should temporary disability and invalidity insurance be extended? The purpose of disability insurance is to provide protection against loss of earnings on account of inability to work because of illness or accident. Since no one is exempt from the possibility of being disabled, it would seem that disability insurance should apply to all gainful workers, the self-employed as well as the employed. Other considerations suggest that the coverage-at least of temporary disability insurance-should be restricted to employed persons. Among employees, incapacity to work is definitely tied to loss of earnings and the amount of loss sustained may be measured by the wages the employee had been receiving. Among self-employed persons, on the contrary, temporary incapacity for work does not ncessarily cause loss of income; an employee or some other member of the family may temporarily carry on the business or enterprise. Also, it may be difficult to ascertain the precise loss which self-employed persons are sustaining because of incapacity. Another obstacle to the inclusion of the self-employed is the difficulty of collecting from them contributions geared to income. These and other considerations suggest that compulsory insurance against temporary disability should be restrictedat least at the outset - to wage and salary workers. Some of the administrative difficulties in the coverage of the self-employed are avoided, though others are created, by the use of flat contributions and flat benefits. 
In the case of invalidity insurance, there is greater need than in temporary disability insurance to extend coverage to all gainful workers; even the self-employed person generally loses the means of self-support when subjected to prolonged illness or permanent disability. Inclusion of the self-employed under invalidity insurance would present the same problem as confronts the inclusion of this group under old-age insurance, namely, the difficulty of collecting contributions and, if benefits are to be geared to prior earnings, of obtaining accurate reporting of earnings. These diffculties may not be insurmountable, and the whole question requires careful study.

\section{Definition of Compensable Disability}

Different definitions of compensable disability and different criteria for judging whether disability exists are necessary in temporary disability and in invalidity insurance. Short-time or temporary disabilities are, in the main, due to acute illness. In such illnesses the question whether the afflicted person is or is not able to work is almost entirely a medical question; a physician must decide whether the person is too sick to work, or whether it would be prejudicial to his health or recovery to attempt to work. In most cases these questions do not present great difficulties. On the other hand, illnesses or conditions which fall within the province of invalidity insurance are, in the main, due to chronic diseases or are the result of accident or injury resulting in permanent dismemberment or loss of function. Here the condition, unlike that in acute illness, tends to remain unchanged or to change slowly. While in some instances the afflicted person will be totally disabled, in many instances there remains some capacity to perform work. The question here is whether the handicapping condition is so serious, the degree of disability so great, that the afflicted person is, by reason of his disability, incapable of substantial gainful work. A useful and practical definition must not be too strict; total disability in the sense of $100 \%$ loss of earning capacity would exclude most permanently disabled persons who cannot earn enough for their own support and the support of those who are dependent upon them.

In short-time illnesses the sick person may be totally or only partially disabled. However, even in the cases of partial disability it would seem unreasonable to judge incapacity by any other test than incapacity to engage in the usual or previous occupation. Thus, in the case of a carpenter who injures' his right hand but who will recover full use of this member in a few weeks, it would seem manifestly unfair to deny him insurance benefits because he might possibly be able to work at something which does not require the use of the right hand. However, when a diseased or handicapping condition is permanent or long-continued, the insurance system is justified in asking whether there is any occupation other than the former or usual occupation in which the afflicted person might engage, and on this basis to decide whether the invalidity benefit should be paid. In such cases there ought to be a shift, in the basis of judging incapacity, from "occupational" incapacity to "general" incapacity. This shift may be made after disability has persisted for a certain fixed period, or it may be made whenever, in the opinion of physicians and the insurance 
authorities, it becomes apparent or reasonably certain that the afflicted person will never again be able to resume his former occupation. The latter procedure is supposed to be the rule in Great Britain under its unified disability insurance system, but in practice the shift is often not made until the rate of benefits is reduced after 26 weeks of disability. In other countries, where temporary disability and invalidity insurance are separate, the transition is made when the disabled person passes from the one system to the other. In most foreign systems of invalidity insurance, the test of incapacity is whether an individual has lost two thirds of his earning capacity as compared with'the earning capacity of individuals of similar training and experience in the same locality; in the German system for salaried workers, the test is loss of $50 \%$ of earning capacity.

In short-time illness, there is generally no question of fitting or retraining the individual for some other occupation. An important interest of invalidity insurance, however, is to ascertain whether, by appropriate training and rehabilitation measures, disabled persons may be made capable of self-support and in requiring such measures to be taken.

\section{Rate of Benefits}

Considerations of broad objectives, economy, and the prevention of malingering dictate that, in general, the amount or rate of benefit in temporary disability should be greater than in invalidity. However, in neither case should the benefit be less than the minimum required for subsistence.

The purpose of the benefit in temporary disability should be to tide the worker over a temporary interruption in earnings with as little alteration of his usual standard of living as possible. Benefits should therefore be a substantial portion of the ordinary earnings of the disabled person. However, full compensation would not be either economically or psychologically advisable; the benefit should be less than the disabled person's earnings. Since temporarily disabled and temporarily unemployed individuals suffer the same wage loss, and since the needs of both groups of workers are approximately the same (except for the question of medical and other sickness costs), there are many obvious advantages in favor of similar benefits for temporary disability and unemployment.

Under most of the state unemployment compensation laws, benefits are paid according to formulas which aim to yield approximately $50 \%$ of the average earnings, with a minimum frequently of $\$ 5$ to $\$ 7$ weekly (or three fourths of wages, whichever is less) and a maximum which in most cases is $\$ 15$ a week. This scale might be adopted for temporary disability so long as it is retained in unemployment compensation. In both temporary disability and unemployment insurance, certain considerations urge an increase in the amount or rate of benefits if the unemployed or disabled person has dependents. The argument for larger disability than unem: ployment benefits hinges on the disabled worker's special need for medical care ${ }_{i}$ special diet, or attendance. 
In invalidity insurance, the rate of benefits, as we have said, ought to be less than in temporary disability. The fact that in many instances the recipient of invalidity benefit will receive this benefit until he dies or becomes eligible for an old-age pension, and that a considerable proportion of these recipients will be in the older age groups, suggests the desirability of calculating invalidity benefits by the same formula as is used for old-age benefits. Under the present federal old-age and survivors insurance system, the monthly old-age benefit for which a retired worker may qualify after age $6_{5}$ is (subject to specified maximums and minimums) equal to $40 \%$ of the first $\$ 50$ of average monthly earnings throughout his insured working lifetime, plus $10 \%$ of the next $\$ 200$ of such earnings, increased by $\mathrm{I} \%$ for each year of covered employment. These benefits are supplemented if the person has a dependent wife over $6_{5}$ and/or dependent children. Use of this formula for compensating invalidity under a joint old-age, survivors, and invalidity insurance system has much to be said in its favor. Such an arrangement would deal more favorably with the employee who, after a lifetime of work, became an invalid than with the younger worker. The coordination with temporary disability benefits would require some special adjustments to assure that the invalidity benefit would not be higher than the temporary disability benefit.

\section{Waiting Period}

In the compensation of disability, a waiting period between the onset of disability and the commencement of benefits is desirable. In the first place, a considerable proportion of all workers lose one, two, or a few days of work each year on account of illness. These losses are so small that the workers can bear them. Moreover, to pay benefits from the first day of disabling sickness would hold out undue inducement to take advantage of the provision. In addition, the compensation of wage loss from illnesses lasting but a few days would very greatly increase the administrative load and would increase the insurance costs beyond the value of the social advantages thereby attained. For example, an analysis of the disability experience of the employees of the Boston Edison Company (which has disability insurance benefits payable from the first day and at the rate of $100 \%$ of wages) over the period $1933-$ I937, inclusive, shows that one-day absences attributed to sickness constitute $23 \%$ of the total number of disabling cases, but account for only $3 \%$ of the total volume of sickness of less than 372 days' duration. Sicknesses lasting seven days or less constitute $83 \%$ of the cases of illness and only $33 \%$ of the volume of all sickness up to 372 days' duration. ${ }^{24}$ It is apparent, therefore, that administrative problems will be greatly reduced and simplified if illnesses of short duration are excluded from compensation.

Many of the factors which need to be taken into account in fixing a waiting period

${ }^{24}$ Gafafer and Frasier, Frequency and Duration of Disabilities Causing Absence from Work Among the Employees of a Public Utility, 1933-1937 (1938) 53 Purlic Healta Reports, No. 30, pp. 1273-1288. The Boston Edison $\mathrm{Co}_{0}$. inaugurated its disability compensation plan in 1913. It compensatcs, totally or partially, loss of wages for disability beginning with the first day. During the second 6 months of membership, an employee is allowed to accumulate sick leave of $\mathrm{I}$ day per month at full pay. After the first year of membership, full pay for continuous disability is allowed for 15 weels; beyond this time compensation is reduced to from three fourths to one fourth of the employec's wages depending upon the number of years of employment with the company. 
are the same in temporary disability compensation as in unemployment compensation, although other factors are different (for instance, the different incidence of shorttime illnesses as compared with short periods of unemployment). At present, the waiting period for unemployment compensation in most states is two or three weeks (cumulative). So long a waiting period is not altogether necessary for temporary disability insurance. Nevertheless, there is much to be said for having waiting periods of the same duration for both programs. In any case, the waiting period for temporary disability must be a period of continuous disability if it is to eliminate the administrative problems of dealing with brief disabilities.

The considerations governing the length of the waiting period for invalidity vary in accordance with whether there is to be a unified or a dual system of disability insurance. If there is a unified system, and the coverage for temporary disability and invalidity benefits is the same, then the waiting period for invalidity benefits could quite properly be the maximum benefit period for temporary disability benefit (except if it is intended that cases found-or declared by statute-to be unquestionably permanent are at once to be made eligible, without waiting period, for invalidity benefit). In other words, when a worker has exhausted his temporary disability benefits, he would, if he meets the stricter criteria of invalidity, automatically transfer to invalidity benefits, presumably at a lower rate. Even if the two systems are not unified they certainly should be coordinated so that invalidity insurance takes on where temporary disability insurance leaves off; there would thus be no gaps between the systems for workers who meet the qualifications for benefits under both systems. If invalidity insurance, by inclusion of self-employed persons, has a wider coverage than temporary disability, then the question of a waiting period for invalidity benefits for workers not entitled to temporary disability benefits needs to be faced on its merits. Otherwise, the question of a desirable waiting period for invalidity benefits is mainly a question of the relationship or coordination of the two systems or the two types of benefits.

\section{Benefit Period}

This presents no problem in invalidity insurance; invalidity benefits should be payable until the person recovers, dies, or qualifies for an old-age benefit. As regards temporary disability insurance, the question of the desirable length of benefit period (i.e., the maximum number of weeks for which benefits would be paid in any one illness or in any single calendar period) is again mainly a question of the desirable relationships between the two insurance systems or between the two types of benefits.

It is important to observe that the financial problems of benefit duration for temporary disability are different from those of unemployment compensation. In the latter, the extension of the benefit period will, in times of severe unemployment, involve a very sharp and perhaps an indeterminate increase in costs; in temporary disability this is not the case. Estimates of the volume of disability under the British National Health Insurance indicate that an extension of the benefit period from 13 to 26 weeks, with a 7 -day waiting period, would increase the costs by $25 \%$. An extension 
of the benefit period from $\mathrm{I}_{3}$ to 52 weeks would increase the costs by $48 \%$. Estimates based on German workmen's insurance experience show that an extension of the benefit period from I3 to 26 weeks would increase the costs by $13 \%$, and an extension from 13 to 52 weeks would increase the costs by $23 \%{ }^{25}$

\section{Eligibility Requirements}

Eligibility requirements are necessary in disability insurance in order to guard the insurance system against adverse selection of risks, and to avoid payment of benefits to individuals who have not had such employment histories as ensure that they are ordinarily gainfully employed or dependent upon their earnings. Under a unified system of disability insurance there would be an advantage in having the eligibility requirements for temporary disability and invalidity benefits the same so that there would be no gaps in the program. On the other hand, because of the greater potential amount of invalidity benefits, as compared with the temporary disability benefit that an individual might draw, there is much to be said for more strict eligibility requirements for invalidity than for temporary disability benefits.

\section{The Costs of Disability Insurance}

The cost of a program of disability insurance may be best approached by considering separately the cost of insurance against temporary disability and against invalidity. In both cases, however, to obtain a precise estimate of the costs involved, it is necessary first of all to define explicitly the coverage of the proposed system or systems, the type or types of disability that will be compensable, the rate of benefits, the waiting and benefit periods, etc. Aside from these factors it needs to be understood that many other factors and circumstances will affect the costs as, for instance, the methods of medical certification employed, the availability and quality of medical care, and the efficiency with which the system is operated.

\section{Cost of Temporary Disability Insurance}

The rate of disability to be expected under an insurance program may be estimated from domestic statistics and from the experience of foreign countries. Illustrative data are summarized below, for males in ages 16 to 64 and for varying waiting and benefit periods. The estimated volume of disability with no waiting period and a 26-week benefit period varies from 4.5 days for the National Health Survey in the United States to 13.8 for Czechoslovakia. From what has already been said it is evident that this is more a range in "compensable" disability (actual or estimated) than in true amount of disability, though socio-economic differences in the populations, differences in the methods of collecting the data, and other differences enter to account for the wide range.

It is important to observe that the experience of the Workmen's Sick and Death Benefit Fund approaches the Manchester Unity experience (English), ${ }^{26}$ which is

25 The differences in the estimates of the increased cost resulting. from an extension of the benefit period, based on English and German sickness experiences, must be attributed largely, if not entirely, to the fact that under the German insurance system as soon as it is established that a worker is permanently disabled he is transferred from temporary disability to the invalidity insurance fund.

${ }^{20}$ This is the experience for a group of British Friendly Societies analyzed by Sir Alfred Watson in 1903. This experience was used later as the actuarial basis of the British National Health Insurance. 
Estimated Annual Days of Compensable Disability Per Individual by Specified Waiting and Benefit Periods, Derived from Various Experiences of Surveys. Males, Ages I6-64. ${ }^{1}$

\begin{tabular}{|c|c|c|c|c|c|c|c|c|}
\hline \multirow{2}{*}{$\begin{array}{l}\text { Waiting period } \\
\text { (days) }\end{array}$} & \multicolumn{8}{|c|}{ Maximum Benefit Period (Weeks) } \\
\hline & 13 & 26 & 39 & 52 & 13 & 26 & 39 & 52 \\
\hline $\begin{array}{r}0 \ldots \ldots \ldots \\
3 \ldots \ldots \ldots \\
7 \ldots \ldots \ldots \\
14 \ldots \ldots \ldots \\
21 \ldots \ldots \ldots \\
28 \ldots \ldots \ldots\end{array}$ & \multicolumn{4}{|c|}{\begin{tabular}{c|c|c|c} 
Workmen's Sick and Death Benefit Fund $^{2}$ \\
5.7 & 6.7 & 7.2 & 7.5 \\
5.0 & 5.9 & 6.4 & 6.7 \\
4.2 & 5.1 & 5.6 & 5.9 \\
3.3 & 4.2 & 4.7 & 5.0 \\
2.8 & 3.6 & 4.0 & 4.3 \\
2.3 & 3.1 & 3.6 & 3.8
\end{tabular}} & $\begin{array}{l}6.2 \\
5.6 \\
4.9 \\
4.0 \\
3.2 \\
2.7\end{array}$ & $\begin{array}{l}\text { Manch } \\
7.5 \\
6.9 \\
6.2 \\
5.2 \\
4.4 \\
3.8\end{array}$ & $\begin{array}{r}\text { Unity } \\
8.2 \\
7.6 \\
6.9 \\
5.8 \\
5.0 \\
4.4\end{array}$ & $\begin{array}{l}8.7 \\
8.0 \\
7.3 \\
6.3 \\
5.4 \\
4.8\end{array}$ \\
\hline $\begin{array}{r}0 \ldots \ldots \ldots \ldots \\
3 \ldots \ldots \ldots \ldots \\
7 \ldots \ldots \ldots \ldots \\
14 \ldots \ldots \ldots \\
21 \ldots \ldots \ldots \\
28 \ldots \ldots \ldots \ldots\end{array}$ & $\begin{array}{l}4.4 \\
3.9 \\
3.4 \\
2.8 \\
2.4 \\
2.1\end{array}$ & $\begin{array}{r}\text { ite ra } \\
5.4 \\
4.8 \\
4.3 \\
3.6 \\
3.2 \\
2.8\end{array}$ & $\begin{array}{r}\text { work } \\
5.9 \\
5.4 \\
4.8 \\
4.2 \\
3.7 \\
3.4\end{array}$ & $\begin{array}{l}6.3 \\
5.8 \\
5.3 \\
4.6 \\
4.1 \\
3.8\end{array}$ & $\begin{array}{l}7.3 \\
6.5 \\
5.4 \\
4.0 \\
3.0 \\
2.7\end{array}$ & $\begin{array}{l}L \\
8.2 \\
7.3 \\
6.1 \\
4.7 \\
3.9 \\
3.3\end{array}$ & $\begin{array}{l}\text { ig } \\
8.5 \\
7.6 \\
6.5 \\
5.0 \\
4.2 \\
3.6\end{array}$ & $\begin{array}{l}8.7 \\
7.8 \\
6.7 \\
5.3 \\
4.4 \\
3.8\end{array}$ \\
\hline $\begin{array}{r}0 \ldots \ldots \ldots \\
3 \ldots \ldots \ldots \\
7 \ldots \ldots \ldots \ldots \\
14 \ldots \ldots \ldots \\
21 \ldots \ldots \ldots \ldots \\
28 \ldots \ldots \ldots \ldots\end{array}$ & $\begin{array}{l}4.1 \\
3.4 \\
2.5 \\
1.8 \\
1.5 \\
1.2\end{array}$ & $\begin{array}{r}\text { tional } \\
4.5 \\
3.8 \\
2.9 \\
2.2 \\
1.8 \\
1.5\end{array}$ & $\begin{array}{c}h S u r \\
4.7 \\
3.9 \\
3.1 \\
2.4 \\
2.0 \\
1.7\end{array}$ & $\begin{array}{l}4.8 \\
4.1 \\
3.2 \\
2.5 \\
2.1 \\
1.8\end{array}$ & $\begin{array}{r}12.3 \\
10.5 \\
8.4 \\
6.0 \\
4.7 \\
3.9\end{array}$ & $\begin{array}{c}\text { Czech } \\
13.8 \\
11.9 \\
9.7 \\
7.3 \\
5.9 \\
5.0\end{array}$ & $\begin{array}{r}\text { oakia } \\
14.5 \\
12.6 \\
10.4 \\
8.0 \\
6.6 \\
5.7\end{array}$ & $\begin{array}{r}14.9 \\
13.1 \\
10.9 \\
8.4 \\
7.0 \\
6.1\end{array}$ \\
\hline
\end{tabular}

1 Adjusted to the age distribution for wage returns in 1937, under the federal old-age insurance system.

2Workmen's Sick and Dealh benefit Fund. IIL. HEALTH INSURANCE CosM'n REPORT (1919).

8(1938) 53 PUBLIC HEALTH REPORTS, No. 15, Pp. 555-573.

U Unpublished data, NATtoNar HEArTB Survey, 1935-1936.

SREPort For 1912 -1913 on the AdMinistration of the National Insurance Act, Part I (Health Insurance) (1913) cmd. 6907 , table 1, p. 593.

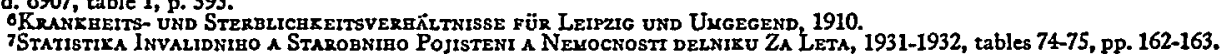

somewhat higher than the experience under the present British National Health Insurance. $^{27}$ The volume of disability is, however, appreciably greater under the Czechoslovakian and German (Leipzig) sickness insurance systems. The relative ranking of the estimated volume of temporary disability is the same for the different benefit periods with a 7-day waiting period, varying from 2.9 days in the National Health Survey to 9.7 under the Czechoslovakian insurance system for a 26-week benefit period.

An extensive study of data illustrated in the table and of other statistics has led us to believe that the volume of disability in Great Britain under the National Health Insiurance may be considered the best guide as to the volume of disability that may be anticipated in this country.

On the basis of the British experience, the volume of temporary disability that may be expected among gainfully employed workers in ages I6 to 64 for persons disabled for more than 7 days but not more than 27 weeks (that is, disabilities lasting 27 weeks in all, including the I-week waiting period) would be approximately 6.5

${ }^{27}$ For a 7-day waiting period and a 26 -week benefit period, the recent British experience is 5.7 days, as contrasted with 5.I days for the Workmen's Sick and Death Benefit Fund, and 4.3 days for railroad workers. 
days per annum per insured worker. ${ }^{28}$ The assumption is made that the contemplated insurance system is to cover all wage earners and salaried workers, with a 7-day waiting period, 26-week benefit period, a qualifying provision having the same degree of strictness as the eligibility requirements of the British system, and a benefit formula essentially the same as for unemployment compensation. On these bases it is estimated that the program would cost about $\mathrm{I} \%$ of payrolls. The average cost per person is not likely to rise appreciably in future years; in fact, with adequate medical provisions there is reason to believe that it may decrease despite the aging of the population.

\section{Cost of Invalidity Insurance}

In order to determine even the general magnitude of costs of invalidity, it is essential' to specify precisely the nature of disability against which protection is to be provided. The volume of compensable invalidity will depend in a large measure on the definition of the degree of disability making a person eligible for invalidity insurance benefits, and also on the administrative practices for the certification of disability.

Another problem peculiar to invalidity insurance and affecting the costs is the need for adequate rehabilitation provisions for workers who would be retrained for other gainful occupations to render them self-supporting, and the problematic estimate of the effectiveness of such provisions adds to the hazards of making a cost estimate.

The determination of the general magnitude of costs in invalidity insurance presents great difficulties, and there is a wide latitude in the bases which may be used in estimating these costs, depending on the detailed specifications of the system contemplated. In invalidity insurance the initial costs are relatively small, but they increase progressively over 15 or more years with the maturing of the system. Moreover, in invalidity the effect of aging of the population is a relatively important factor which cannot be neglected, because the incidence of invalidity is much higher among older than among younger persons. Despite these uncertainties, the general magnitude of the immediate and future costs can be determined within reasonable margins of error.

For present purposes, and by way of illustration only, the assumption is made that the system would cover all, or substantially all, employed persons; that only those workers would be entitled to benefit who have lost two thirds or more of their earning capacity for any form of gainful work; that judgment of the extent of disability would be made by the insurance authorities; that the benefit period would begin after the twenty-seventh week of disability and would terminate upon death, attainment of age 65 , or whenever re-examination indicated a change in the patient's condition disqualifying him for the benefit; that the benefit formula would be the same as the present formula for old-age insurance; and that there would be qualifying provisions equivalent to "fully" and "currently" insured status in the present old-age and survivors insurance system.

${ }^{28}$ For both sexes-not merely for males, to which the table is limited. 
On these bases it is estimated that the annual cost of invalidity insurance would probably never exceed $\mathrm{r} \%$ of the taxable income unless the definition of compensable invalidity is liberalized and the administrative restraints are relaxed considerably beyond the specifications assumed here. Some actuarial estimates place the cost, after about 40 years, as high as $1 / 3 \%$ of payroll for a system with the assumed specifications. With more rigid requirements than we have assumed, limiting compensation, for example, to those who have lost $90 \%$ or more of earning capacity for any form of gainful work, these costs would be substantially lowered-by one third or more.

\section{Total Costs}

In general, it may be said that a system of disability insurance protection applying to both temporary disability and invalidity insurance, with the specifications indicated, would, at least for some considerable period of years in the future, require somewhat less than $2 \%$ of the payrolls of covered individuals. To raise the necessary revenues to meet the costs for temporary disability and invalidity insurance, the costs might be shared by employers and employees, as in the present old-age and survivors insurance, with possible participation by the federal government through appropriations from general, revenues. It must not be assumed, however, that the entire amount would constitute new expenditures. At present a substantial part of the relief and assistance expenditures made by federal, state, and local governments go to families which have lost their economic independence because of disabling disease. Despite these substantial expenditures, the security that is now provided is tenuous, uncertain; and haphazard in its operation. Through properly implemented temporary disability and invalidity insurance, the risks of disability could be more effectively provided against, and the protection would be free from many undesirable effects of relief. 